\title{
LINGUAGEM DO BONECO/TÍTERE PELO OLHAR DO DESIGN: CONTRIBUIÇÕES DO DESIGN PARA O TEATRO DE BONECOS
}

Eduardo de Andrade Oliveira

Pontifícia Universidade Católica do Rio de Janeiro (PUC-Rio)

arte5@terra.com.br

Jackeline Lima Farbiarz, Profaㅡ Dra

Pontifícia Universidade Católica do Rio de Janeiro (PUC-Rio)

jackeline@puc-rio.br

Vera Nojima, Profa Dra

Pontifícia Universidade Católica do Rio de Janeiro (PUC-Rio)

nojima@puc-rio.br

Resumo: Adota-se neste artigo a definição da historiadora Magda Modesto para boneco e títere. Segundo a autora, "boneco" seria apenas o objeto inerte; mas no momento em que é manipulado e ganha movimento, este se torna "títere". Entende-se o boneco/títere como fenômeno de linguagem impregnado de significações em seu aspecto formal e em sua ação dramática, sendo assim esta pesquisa se pretende a oferecer aos designers de bonecos, artesãos e pessoas afins, considerações importantes que devem ser observadas na hora de se projetar uma personagem. As ações que envolvem o projeto de um boneco/títere devem ser orientadas para que o espectador tenha um entendimento próprio da mensagem proposta. Embora este entendimento dependa do repertório do espectador, cabe ao designer de bonecos encontrar meios que facilitem esta leitura. A matéria utilizada na confecção de um boneco, o processo técnico de construção, o conhecimento dos sistemas de significação e a habilidade e experiência do designer no momento de projetar uma personagem são determinantes para a configuração (projeto), conformação (forma), entendimento das funções simbólicas (conteúdo - significado) e ação cênica (tema - função) deste objeto (boneco) e do seu uso em cena como artefato comunicativo (títere).

Palavras-chave: Boneco, Títere, Design de Bonecos, Linguagem do Boneco.

Abstract: This article adopts historian Magda Modestos's definition of puppet and titere. According to the autor, "puppet" would be only the inert object; but when it is manipulated, and gains movement, it becomes "titere". It is understood the puppet/títere as imbued with meaning in its formal aspect (configuration/ conformation) and dramatic action. It aims to offer the puppet designer, craftsmen and like-minded people, important tools that should be considered at the time to design a character. The 
actions that are part of the puppet/titere universe are created so that the viewer reflect on the action presented and have a message of understanding own proposal. Although this understanding depends on the viewer's repertoire, it is the puppet designer find ways to facilitate this reading. The material used in the making of a doll, the technical process of construction, knowledge of systems of meaning, the ability and experience of the designer when designing a character, are decisive for the configuration / conformation of this object (puppet) and its use as a communication device (titere). In the case of dolls design it is necessary to reveal aspects of configuration (design), conformation (shape) and master the symbolic functions (content - meaning) involving the use of this communication object within a scenic action (theme - function).

Keywords: Character Design, Puppets, Puppet Design, Puppet's language.

\section{INTRODUÇÃO}

Entende-se aqui o boneco/títere como um objeto dotado de características intrínsecas que inspiram reflexões nas mais diversas áreas de conhecimento. Uma apresentação de sua história pode ser encontrada nos textos de Borba Filho (1987), Amaral (1996), Curci (2002), Blumenthal (2005), entre outros. Bonecos inspiraram filósofos e pensadores como "Xenofonte, Luciano, Homero, Sócrates e Plutarco e sabese que um certo Potino dava espetáculos desse tipo no Teatro de Dionísio" (Borba Filho,1987:21). Presente em todas as áreas de conhecimento, o boneco/títere está nas Artes Plásticas, na Filosofia, nas ciências que estudam sua materialidade, na Linguística, etc. Propõe-se aqui uma investigação, ainda pouco explorada, deste objeto pelo viés do Design por meio de um levantamento bibliográfico, análise de conteúdo e proposição de parâmetros de projeto para designers de bonecos.

Inclui-se o boneco/títere na tríade do Design da forma, significado e função a partir de textos de Bonfim (2014), Ostrower (1990), Sudjic (2008) e Farbiarz (2014); e o apresenta também como fenômeno de linguagem segundo a teoria de Peirce a partir de textos de Santaella, Braida e Nojima (2014). Os fenômenos de linguagem são abordados pelos autores Bakhtin (2014), no que se referem à composição dentro do gênero, tomando como referência de análise os conceitos de estágio superior, o tema; e o estágio inferior a significação; e Cassirer (2001) quanto às formas simbólicas.

O artigo enquadra este objeto como signo/linguagem através da adaptação de conceitos da Semiótica. Podemos conceituar a semiótica como "a ciência geral dos signos ou ciência da significação, ou ainda, a ciência que estuda todas as linguagens" (Braida e Nojima, 2014:27). Entende-se aqui que o boneco/títere é impregnado de significações tanto em seu aspecto formal (configuração/conformação) quanto em ação dramática (signo em movimento), constituindo, assim, linguagem. Segundo Curci a representação ou manipulação de um boneco transmite "a su vez [] uma serie de signos que integran un lenguaje" (Curci, 2002:52). É a partir destes fundamentos que se propõe aqui uma investigação deste objeto comunicativo pelo olhar do Design.

O boneco é configurado por um conjunto de signos e representa personagens percebidos e identificados por sua forma. Quando em cena, o títere (signo em movimento), ganha outras características simbólicas: a força empregada pelo 
manipulador, as reações do títere em cada momento dramático, as posturas corporais do boneco e do manipulador, além de elementos externos como cenário, sonoplastia, iluminação, elementos que compõem a ação dramática criando uma narrativa.

Os bonecos/títeres são um fenômeno de linguagem, ou seja, "são mensagem e/ou produzem mensagem, são constituídos por meio de signos e sistemas de signos, os quais são capazes de gerar significados" (Braida e Nojima, 2014:50).

Transferindo para nosso objeto de estudo o conceito de estruturas do código, (Santaella, 2014:116) onde a autora apresenta os signos icônicos da fotografia divididos em primeiro e segundo plano de articulação, ou seja, passíveis de interpretação a partir do entendimento do código e da linguagem, pode-se anunciar o seguinte pensamento:

Os signos icônicos do objeto/boneco consistem em um código, uma linguagem. No primeiro plano, esse código contém os chamados morfemas icônicos como unidades mínimas portadoras de significado no boneco. Estas são unidades definidas somente pelas condições de percepção das características formais do boneco e ainda não por sua analogia referencial. Primeiro toma-se o boneco como um todo, seria o que Pierce (apud. Braida e Nojima, 2014) define como primeiridade dando à experiência uma qualidade distintiva. Na segundidade esses morfemas icônicos vão sendo lidos a partir de relações mais complexas ; passa-se a identificar o boneco por seu caráter factual. Finalmente, na categoria de terceiridade tem-se uma "síntese intelectual, correspondendo à camada de inteligibilidade, ou pensamento e signos, através da qual representamos e interpretamos o [...] boneco." (Braida e Nojima,2014:24).

A seguir apresentamos o desenvolvimento da pesquisa: investigação e análise do objeto boneco e seu caráter comunicacional pelo olhar do designer de bonecos.

\section{2 - DESENVOLVIMENTO}

O boneco/títere é uma personagem. Sua criação e confecção se dão para atender a uma narrativa e, além disto, ele é uma das mais antigas representações da expressividade humana, sendo os "símbolos figurativos iniciais, as estilizações dos deuses, ou as forças da natureza, os primeiros disfarces dos feiticeiros, as primeiras máscaras" (Revista Mamulengo $\mathrm{n} \cong 12$, 1984:32). Sua origem, segundo a maioria dos historiadores que tratam do assunto, está na magia, nos rituais de fertilidade, no desejo humano de representar aquilo que se espera acontecer na realidade.

O teatro de bonecos é uma forma dramática na qual figuras ou objetos são animados direta ou indiretamente. Em sua origem, o teatro de bonecos esteve muito ligado às crenças religiosas, às primeiras tentativas humanas de se relacionar com o desconhecido, com o mundo além deste, extra-terreno. Os meios utilizados eram símbolos: máscaras, objetos ou figuras representando a pessoa humana. "Era a magia, ou seja, a nossa natureza colocada noutra dimensão". (Amaral, 1984:28).

São muitas as definições de boneco:

"Cualquier objeto movido em función dramática" (Buffano, apud Artiles,1998:15)

"Boneco é o termo usado para designar um objeto que, representando a figura humana, animal ou abstrata, é dramaticamente animado diante de um público" (Amaral, 1996:71).

"Objeto que a su vez transmite una serie de signos que integran un lenguaje" (Curci,2002:52) 
A historiadora Magda Modesto, entrevistada em dezembro de 2006, defende, por sua vez, que "o boneco é apenas o objeto, inerte. Quando este objeto, que pode ser qualquer coisa, ganha a energia do manipulador, passa a ser um títere".

Para fins deste artigo, portanto, passa-se a considerar Boneco: objeto inerte/inanimado e Títere: boneco que se faz mover ou gesticular.

\subsection{0 objeto boneco}

Na contemporaneidade, trata-se primeiramente de um objeto cênico. Todo boneco é construído para cumprir algum objetivo, para ser manipulado, tocado, atender sua função de signo em movimento. Conforme nos coloca Curci: "El títere es un objeto construido para la escena, más específicamente para la acción dramática, con el propósito de establecer una comunicación definida con un interlocutor: el público" (Curci,2002:18).

A configuração do projeto e a conformação imposta pela forma do boneco revelam seu enquadre dentro desse espaço cênico. Ele pode representar a figura humana, animal ou abstrata e é formado por partes articuladas ou fixas, que se apresentam ao público através da mediação de um manipulador.

Entende-se que o boneco é uma conformação da matéria (forma) e o títere um objeto com significado e função (conteúdo), portanto uma unidade entre forma e conteúdo. O conteúdo é a essência do objeto/boneco, isto é, o conjunto de elementos que definem sua natureza e utilidade enquanto títere.

"No sentido comum entende-se como forma, a figura externa, a manifestação superficial e visível de coisas e processos da realidade objetiva. [] Forma é finalmente compreendida como os limites exteriores da matéria de que se constitui um corpo, e que a este conferem feitio, configuração, aspecto particular". (Bonfim, 2014:33).

Já para Ostrower o conceito de forma, embora seja também algo em si delimitado, não se resume a uma área unicamente demarcada por fronteiras. Segundo ela, "a forma é o modo por que se relacionam os fenômenos, é o modo como se configuram certas relações dentro de um contexto" (Ostrower,1977:79). A forma é aqui entendida como uma "estrutura de relações" correspondendo ao "conteúdo significativo das coisas".

Refletindo-se sobre estes dois conceitos, que se complementam, e aplicando-os ao objeto de estudo, pode-se colocar o objeto boneco enquanto forma nas palavras de Bonfim e o títere enquanto forma nas palavras de Ostrower. Sendo assim, a figura externa do boneco (sua forma objetiva) ganha conteúdo significativo ao ser usado como títere. Entende-se aqui que o boneco também possui conteúdo significativo em sua forma, mas este só se completa quando ele está em movimento, quando ganha a alma do manipulador.

O objeto de estudo deste artigo é o boneco/títere. Independente das definições de boneco, estamos tratando aqui de um objeto, de uma coisa construída e utilizada como meio de representação. A coisa boneco está configurada em uma forma (conformada). Segundo Bonfim, o termo configuração deve ser entendido ora como atividade (configurar), ora como o resultado desta atividade, a figura. (Bonfim,2014:18). Entende-se aqui figura como o projeto a ser conformado em boneco, tornando-se a própria forma em si. A configuração seria assim um estágio anterior à conformação. 


\subsection{0 títere}

O títere está a serviço de uma personagem dentro de uma narrativa e, portanto, deve ser reconhecido como tal. Por este motivo o títere deve possuir características que permitam uma identificação com a personagem, integrando e manifestando o imaginário que a envolve. $O$ designer é um dos profissionais que corroboram com o projeto e a realização do objeto - neste caso, a construção de bonecos. Portanto, se pensarmos que a materialidade e a visualidade do suporte influenciam na recepção do conteúdo, é possível compreender o "designer de bonecos" como um importante mediador na relação entre o receptor e o objeto.

Assim, diante da mediação que exerce entre o objeto e o receptor por meio da configuração formal do suporte, o designer deve conjugar variáveis relativas às intenções da narrativa. Coloca-se aqui intenções da narrativa como sendo as referências para as construções formais, os "atributos dos personagens [bonecos] e sua significação" (PROPP, 1984:81), e estes bonecos, inseridos portanto numa situação determinada pela narrativa, são construídos com o objetivo de representarem visualmente suas personalidades. ${ }^{1}$ Para esta representação, o domínio do material e suas características físicas é fundamental. É este domínio que vai garantir uma justa adequação entre a intenção de comunicar e o resultado captado pelo espectador.

"A importância do conhecimento profundo do material, aliada à outra parte teatral, é que realmente vão dar a ânima, que vai ser reconhecida pelo espectador. Cria-se a solução técnica pelo domínio do material. Então o domínio do material é básico. É um fato a ser marcado esta questão do material". (Modesto,2006) ${ }^{2}$

A representação material da forma (sua configuração/conformação) é dada com a manipulação e o domínio completo dos meios físicos disponíveis no momento justo da representação. Trata-se, portanto, de:

- Apropriação do material para uso da configuração (projeto);

- manifestação (conformação) do imaginário com o domínio do material (forma)

- confecção do objeto (a coisa configurada/conformada - FORMA), agora dotado de uma conceituação simbólica (SIGNIFICADO) dentro de um contexto dramático (conteúdo/tema - FUNÇÃO).

O boneco extrapola a mera representação, passando a representar um pensamento aprisionado naquela conformação. Sendo assim, o estudo da figura de um boneco envolveria também a sintática (forma, material, cor, textura, etc.), a semântica (o conteúdo ou essência do boneco) e a pragmática (objetivos, finalidades, valores narrativos).

Para ilustrar o uso destas terminologias da lingüística na criação de uma personagem, apresentamos a figura 1 . Um boneco com bigode pode ser qualquer personagem que tenha bigode. Estaria, portanto, numa função sintática, numa configuração formal. Uma vez que adicionamos na personagem outro elemento, como cabelo e chapéu, passamos a identificá-la por sua função semântica. A personagem agora possui um conteúdo simbólico, passamos a ler a essência do boneco. Podemos a partir de um repertório construído pela função pragmática, identificar condutas de comportamento para cada uma dessas personagens. A personagem da esquerda é

\footnotetext{
${ }^{1}$ O semiólogo russo Vladimir Propp define como atributos das personagens as qualidades externas de personagem, ou seja, sua configuração exterior, aparência e maneiras de agir.

${ }^{2}$ Modesto em entrevista ao autor (Rio de Janeiro, 2006).
} 
facilmente identificada como uma representante do poder opressivo. Podemos associar a figura central como uma personagem lírica, sonhadora e a última figura como a de um inventor. São associações construídas pelo repertório histórico e que devem ser consideradas na hora de se projetar um boneco.

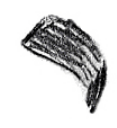

19.4.

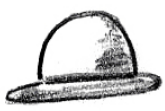

14

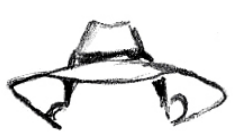

4.

Figura $1 \mathrm{Um}$ mesmo bigode pode pertencer a personagens completamente diferentes com a simples aplicação de outro ícone. São signos que envolvem o projeto de um boneco. (Eduardo Andrade, 2007) "Elaborado pelo autor, com base na pesquisa realizada".

Todos os ícones colocados vão conter significados que passam a identificar o boneco dentro do contexto narrativo e dentro da ação dramática. A simples experimentação de aplicação de diferentes bigodes no mesmo suporte formal de cabeça pode fornecer leituras de personalidades diferentes. Este fenômeno se dá pelo reconhecimento icônico da forma bigode. Entende-se aqui que esse reconhecimento icônico não é suficiente para a caracterização completa da personagem, mas já demonstra um possível caminho nessa caracterização.

Essa é, sem dúvida, uma leitura "plana" para a personagem, isto é, uma generalização baseada nos atributos da personagem (no caso, a aparência) que são comuns a elementos de certo grupo social ou a um estereótipo. ${ }^{3}$ Sabemos, no entanto, que uma característica icônica muitas vezes não é suficiente para enquadrar essa imagem, por exemplo, dentro de uma narrativa. Alguns atributos da personagem são fundamentais.
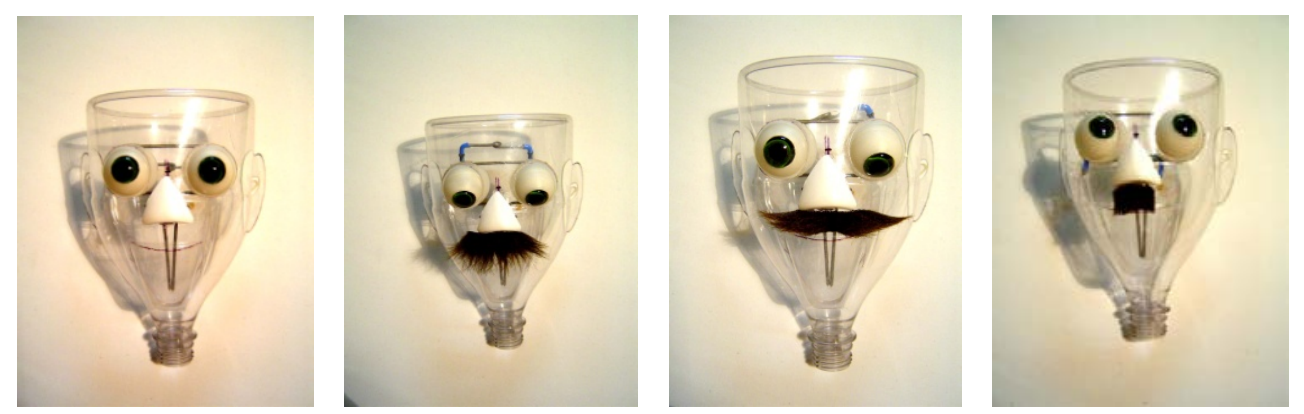

Figura 2 Experiências de aplicação de diferentes desenhos de bigode em cabeça de boneco construída em PET. Variando o desenho do bigode, variamos também o tipo de personagem plana que o boneco representa. "Elaborado pelo autor com base na pesquisa realizada".

\subsection{Boneco/Títere e Design}

Antes de prosseguir faz-se necessário reforçar por que se considera, neste artigo, o boneco como objeto de estudo do design. Bonfim afirma que a atividade do design "objetiva a configuração de objetos de uso e sistemas de informação" (Bonfim,2014:17) e que sua prática se desenvolve segundo princípios científicos.

\footnotetext{
3 Personagens planas são "seres íntegros e facilmente delimitáveis, marcados duma vez por todas com certos traços que os caracterizam" (CANDIDO, 2004:60).
} 
"Através do uso de ferramentas científicas o designer praticamente abandonou a tradição, a maestria do artesão e o senso comum, características típicas da configuração no período pré-industrial, e passou a aplicar outros conhecimentos que permitem antecipar no plano teórico e representativo concepções formais para problemas de projeto". (Bonfim, 2014:36)

Embora Bonfim nos apresente que o designer abandona a maestria do artesão, o que pareceria contraditório ao projeto do boneco que ainda carrega em seu fazer um processo artesanal, construir bonecos requer uma metodologia que exige pesquisar materiais, encontrar solução de movimentos adequados que correspondam à necessidade da trama; buscar o ajuste ergonômico para o manipulador; estudar as articulações, estruturas e, finalmente, elaborar o próprio visual do boneco, que deve ter uma relação direta com o tipo de personagem que este representa. Cada boneco, portanto, concentra em si um método de pesquisa e confecção, um projeto de design (Figura 3).

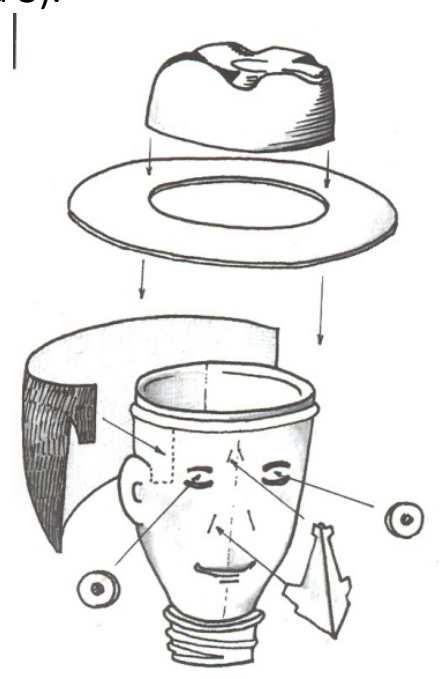

Figura 3 A Conformação de um boneco a partir do acoplamento de elementos diversos. Cada elemento possui uma forma para cumprir uma função dentro da forma total do boneco.

Elaborado pelo autor, com base na pesquisa realizada (Oliveira, Eduardo. 2007/ PupPet - Bonecos de PET).

Mesmo não sendo produzido em série, como se esperaria de um produto de design, cada boneco é em si um protótipo e um produto final único que traz todas as etapas de projeto e construção pertencentes ao universo do design. Estando essas etapas inseridas em um método de pesquisa, a criação de um boneco passa de uma realização artesanal intuitiva para um produto solucionado dentro de um pensamento de design. A Figura 4 nos dá outro exemplo de como o designer pode contribuir com o projeto de personagens. A partir da manipulação da materialidade presente (resíduos plásticos), da investigação de suas possibilidades, das soluções de acoplamento e dos mecanismos de fixação projeta-se um boneco. A investigação feita pelo designer de bonecos deve ter sempre um caráter científico, um objetivo claro de representar no boneco a personagem pensada. 


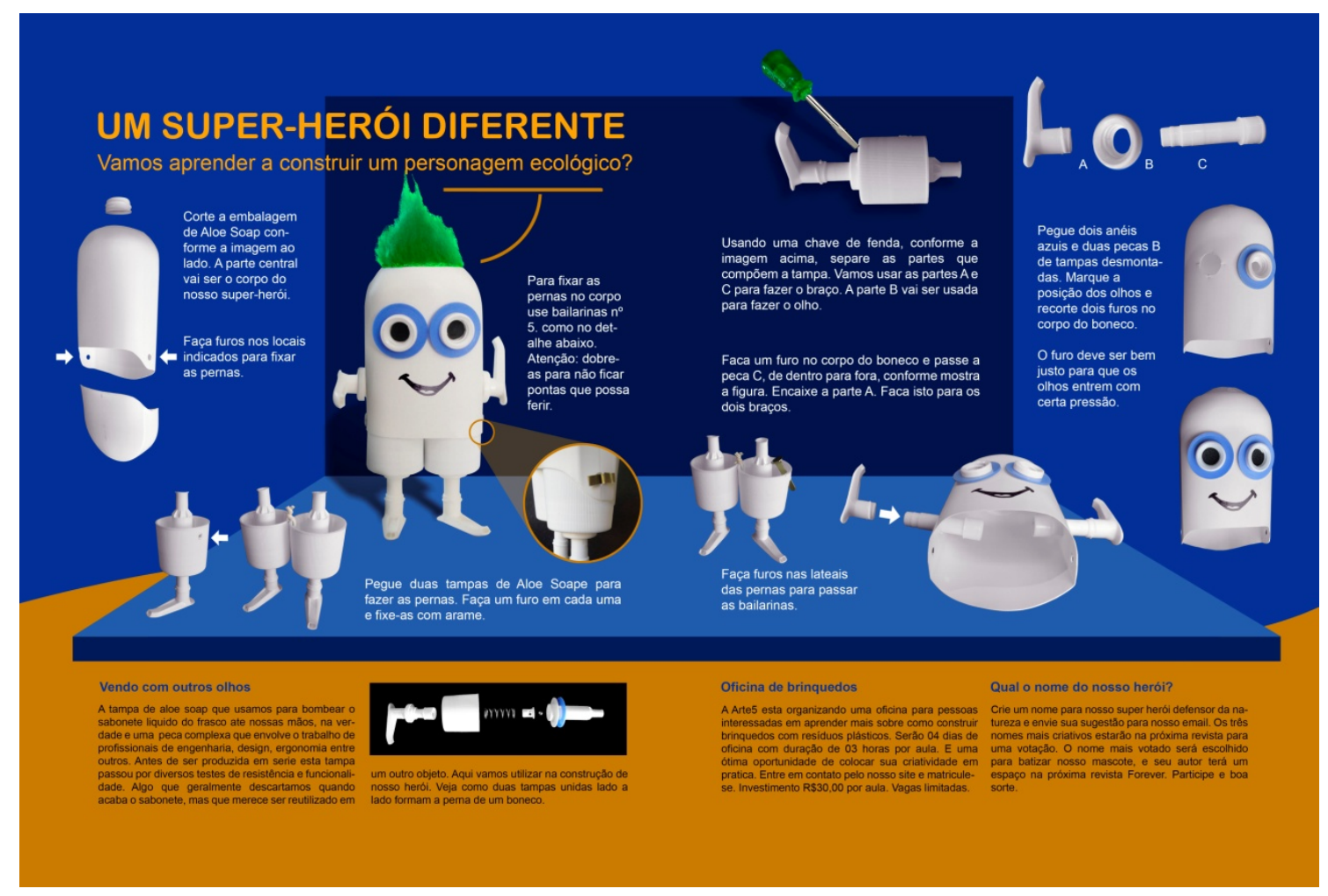

Figura 4 "Elaborado pelo autor, com base na pesquisa realizada" (Oliveira, Eduardo Andrade, Revista Forever, 2011:150/151)

Uma vez conferido ao boneco seu enquadre enquanto objeto projetado pelo designer, passa-se a enquadrar sua configuração segundo conceitos da linguística e da semiótica. Entende-se aqui que estes conceitos ajudam o designer na hora de projetar o boneco.

Numa reflexão sobre a semiótica do boneco, contribuindo com os estudos de Rafael Curci sobre o que ele chama de "sinécdoque del títere" (Curci,2002:64), vê-se aqui o boneco como signo. Considera-se, na Figura 5 - Esquema I, o boneco enquanto objeto configurado por um conjunto de signos, que representa personagens percebidos e identificados por sua forma (o representamen do triângulo de Peirce), por seu significado (personagens Tipo), e por sua função (o títere em ação). Bonecos possuem características intrínsecas (significados), constituem uma linguagem, representam personagens do imaginário humano, são identificados e significados pelos agentes envolvidos na prática com o boneco, formam uma representação mental. Títeres contam histórias, produzem narrativas. Boneco e títere cumprindo sua função de "Signo Ambivalente, [] un objeto que, movido en función dramática simula vida, y al mismo tiempo, se percibe como algo espurio, inorgánico, artificial. [] es inanimado y sin embargo parece vivo". (Curci, 2002:54). 


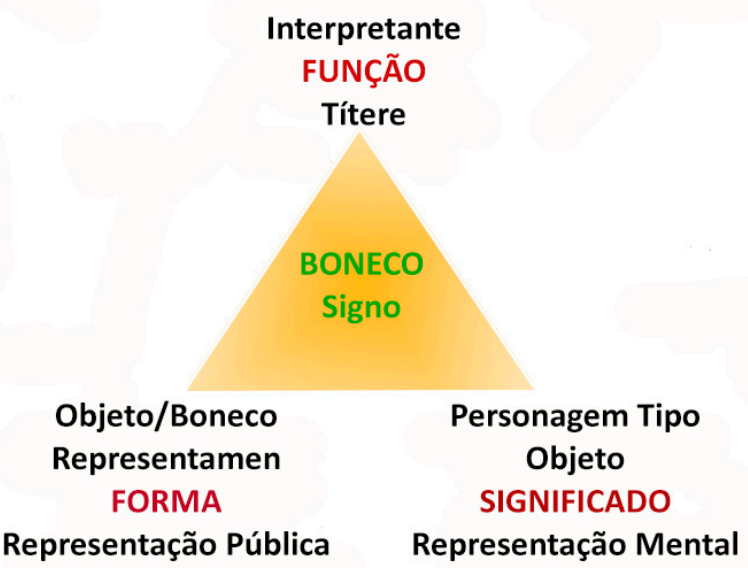

Figura 5 - Esquema I

Pesquisa-se aqui o boneco como um conjunto de signos e o títere como fenômeno de linguagem. Santaella e Nöth apresentam Representação como Signo (1997:16). O boneco é um objeto cênico projetado para ser manipulado em uma ação dramática; uma representação. Entende-se aqui que o boneco é construído por um conjunto de signos que reunidos passam a representar um signo maior. Quando em ação cênica, o signo boneco se converte em linguagem, por meio de uma narrativa dentro da dramaturgia. (Figura 6 - Esquema II).

Por pertencer a dois momentos distintos, de um lado como objeto inanimado, inerte (boneco) e do outro como objeto dotado de vida pela ação do manipulador (títere) apresenta-se aqui também o títere como signo dentro da tríade semiótica de Peirce. Esta análise apresenta ao designer de bonecos parâmetros importantes no projeto deste objeto comunicativo. Enquanto o boneco possui funções significativas intrínsecas à configuração e conformação do objeto em si, o títere amplia essas funções significativas ao somar a energia do manipulador com o contexto da encenação; e elementos externos que compõem a representação (cenário, iluminação, sons, etc).

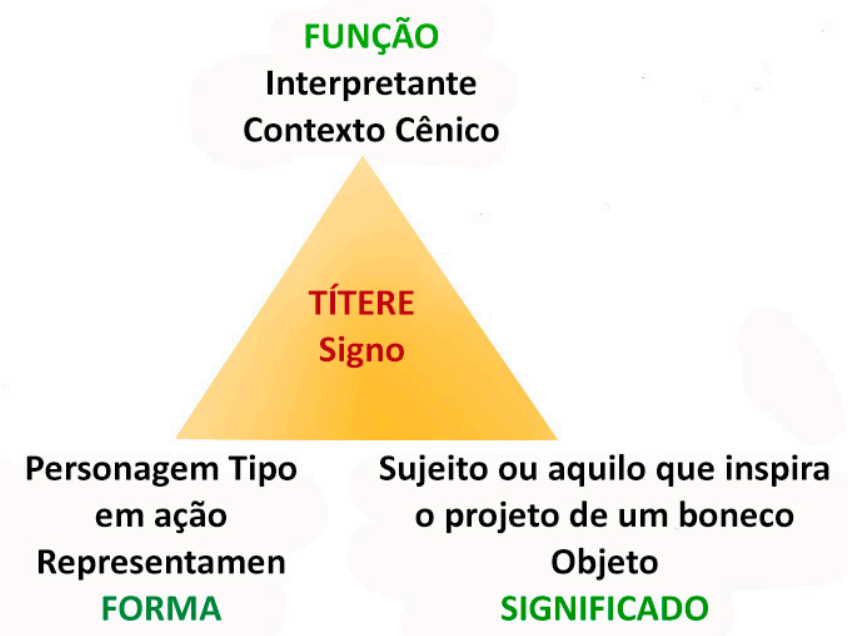

Figura 6 - Esquema II Figuras 5 e 6 adaptadas de (Nojima e Braida, 2014: 25) 

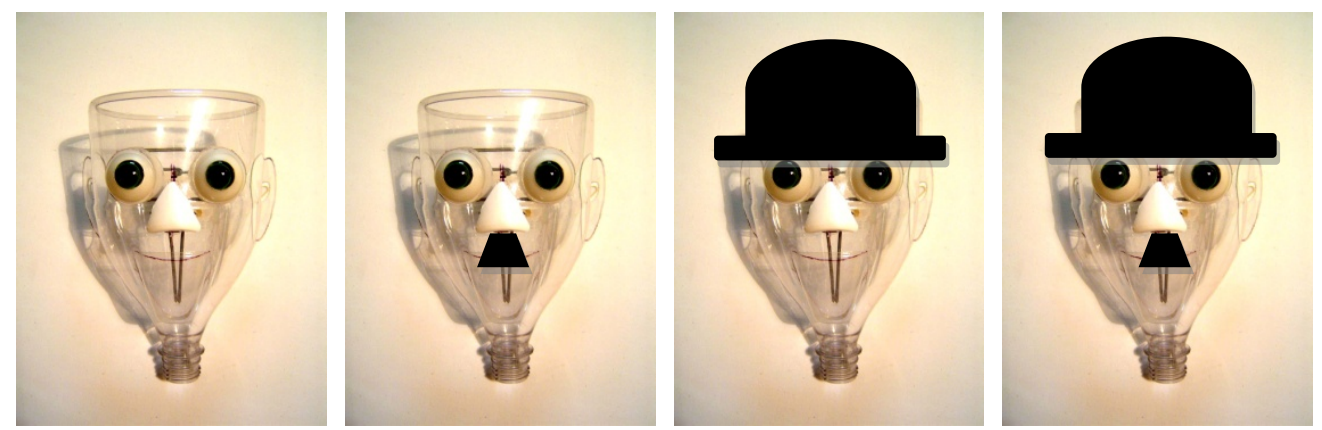

Figura 6 - Composição por morfemas icônicos (bigode e chapéu) gerando um supermorfema (Personagem). Os supermorfemas pertencem à terceiridade, isto é, são identificados e traduzidos dentro de um contexto cultural. São inúmeras as possibilidades de combinação dos morfemas icônicos ,mas nem sempre vão gerar supermorfemas.

Elaborado pelo autor, com base na pesquisa realizada.

\section{3 - CONCLUSÃO}

Investiga-se neste artigo as relações do boneco/títere com os conceitos de forma, significado e função (provenientes dos estudos do design); os conceitos das categorias universais de Peirce (para o projeto e conformação do objeto/boneco); e os conceitos de Tema e Composição em Bakhtin (ao colocarmos o boneco/títere como fenômeno de linguagem). Entende-se aqui que estes conceitos são, como afirma Nojima (em um outro contexto), "interdependentes e não devem ser pensados de maneira isolada, pois eles se interferem mutuamente". (Braida e Nojima,2014:85). O designer de bonecos ao projetar este objeto deve levar em consideração as relações estabelecidas por essas categorias conceituais. Defende-se aqui que a articulação e domínio desses conceitos são fundamentais para que o designer de bonecos alcance os objetivos esperados com seu projeto.

Assim, partindo da questão da forma (boneco) enquanto manifestação de uma idéia; do significado (personagem) enquanto afirmação de um conteúdo; e da função (objeto/personagem) produzindo um entendimento mais amplo a partir do referencial histórico (Tema) dos agentes envolvidos com sua prática, procurou-se neste artigo investigar o objeto/boneco pelo viés do Design.

O designer de bonecos deve projetá-lo a partir de parâmetros que garantam um entendimento do maior número possível de receptores da informação. Estamos falando de algo que se quer comunicar. O boneco sempre foi usado como um suporte, um veículo para a comunicação. E se esta comunicação é entendida de forma diferente de acordo com o projeto, a materialidade e a manipulação dos bonecos, cabe ao designer prever todas estas inter-relações na hora de projetar. Ao observar que a construção artesanal de um boneco contribui com um processo narrativo - e, portanto, coloca este objeto/boneco inserido em um contexto onde é transmitido um determinado conteúdo - podemos afirmar que este objeto é um suporte que contribui para a aquisição de conhecimentos e construção de linguagens. 


\section{REFERÊNCIAS}

ALCURE, Adriana Schneider. Mamulengos dos Mestres Zé Lopes e Zé de Vina. 2001. 232f. Dissertação de mestrado. Universidade do Rio de Janeiro / UNIRIO, Centro de Letras e Artes, Programa de Pós-Graduação em Teatro

AMARAL, Ana Maria. Teatro de formas animadas: máscaras, bonecos, objetos. São Paulo: Editora da Universidade de São Paulo, 1996 - (Texto \& Arte, 2).

ARGAN, Giulio Carlo. A história na Metodologia do Projeto. Revista Caramelo no6, 1992

BAKHTIN, Mikhail. Marxismo e Filosofia da Linguagem. São Paulo: Editora Hucitec, 2014

BENJAMIN, Walter. Reflexões: a criança, o brinquedo, a educação. São Paulo:

Summus, 1984, vol. 17.

BENJAMIN, Walter. Rua de mão única: obras escolhidas. São Paulo: Editora Brasiliense, 1987, vol. 2.

BONFIM, Gustavo Amarante. Uma coletânea. Rio de Janeiro. Rio Books, 2014.

Organização:COUTO, Rita; FARBIARZ, Jackeline Lima; Novaes, Luiza.

BORBA FILHO, Herminio. Fisionomia e espírito do mamulengo. Rio de Janeiro: INACEM,1987.

BRAIDA, Frederico; NOJIMA, Vera Lucia. Tríades do design: Um olhar semiótico sobre a forma, o significado e a função. Rio Book's 2014.

BRAIDA, Frederico; NOJIMA, Vera Lucia.Por que design é linguagem? Rio Book's 2014.

CASSIRER, Ernst. A filosofia das formas simbólicas: I - A linguagem. São Paulo: Martins Fontes, 2001.

COELHO, Luis Antonio L.; WESTIN, Denise (Orgs.). Estudo e prática de metodologia em design nos cursos de pós-graduação. Rio de Janeiro: Novas Ideias, 2011.

COUTO,Rita Maria de Souza;Farfiarz, Jackeline Lima; Novaes, Luiza. Gustavo Amarante Bonfim uma coletânea. Rio Book's 1ạ Edição 2014.

COUTO, Rita Maria de Souza et al. (Orgs.). Design em situações de ensinoaprendizagem: 20 anos de pesquisa no laboratório interdisciplinar de design/educação. Rio de Janeiro: Rio Book's, 2014.

CURCI, Rafael. De los objetos y otras manipulaciones titiriteras. Buenos Aires, Argentina: Tridente Libros, 2002.

MODESTO, Magda. Entrevista concedida pela Profa Magda Castanheira Modesto.

Pesquisadora (Rio de Janeiro) . 2006

MOREIRA, Luís Eustáquio; RIPPER, José Luis Mendes. Lógica do objeto natural. Rio de Janeiro: Nau Editora, 2014.

OSTROWER, Fayga. Criatividade e Processos de Criação. Rio de Janeiro: IMAGO 1997

PORTINARI, Denise. 0 kan e a espada: por uma retomada da noção de intuição na metodologia projetual, 2011.

SUDJIC, Deyan. A linguagem das coisas. Rio de Janeiro: Intrínseca, 2010. 